\title{
Deforestation in uganda: population increase, forests loss and climate change.
}

\section{Josephat M*}

Petroleum Production and Geoscience- Makerere University, Dip. Wildlife and Natural Resources- Uganda Wildlife Research \& Training Institute, Uganda

\begin{abstract}
Besides that, Africa Natural Resources Institute (ANRI) is delighted to host the 3rd edition of the high level conference on minerals and petroleum at a continental level following the unquestionable success of the second focusing on African Great Lakes Extractive Industry amidst of ongoing climate change challenges. This confirms the importance of ANRI's contribution to the development of these long term untapped resources which show promising growth prospects to the continent. As development plans match a head for oil production in kenya, Uganda, with huge gas investment in Tanzania and Mozambique on addition to already producing countries like Nigeria, Angola, this has made the continent to attractive to international oil companies. In order to realize the potential of extractive industry and other opportunities related to the sector and associated challenges, there is a great need to address them in start as a precursor for good planning to ensure effective exploitation and benefit maximisation.
\end{abstract}

Keywords: climate change, deforestation.

Accepted on April 04, 2018

\section{Introduction}

Regarding the forest sector in Uganda, in the last one or so decades, Uganda has carried out several Policies, Legal and Institutional Reforms aimed at promoting the conservation and sustainable use of the country's forest resources.

Among the key reforms include:

1. Putting in place of the National Forestry Policy 2001.

2. Enactment of the National Forestry and Tree Planting Act 2003.

3. New institutional arrangements including the Forest Sector Support Department, the National Forestry Authority.

4. District Forestry Services being made.

To address the question of enforcement in the forestry and other environment sub-sectors, Government also established the Environmental Protection Police Unit.
Despite these interventions, the country continues to lose forest cover at a very alarming rate. While for many years it was reported that Uganda was losing approximately 90,000 hectares between 1990 and 2010 of forest cover annually (Figure 1).

However, the recent studies conducted by Africa Natural Resources Institute indicate that forest cover loss has now increased to an estimated 200,000 hectares annually.

The situation is being blamed partly on Uganda's booming population, which is growing at a rate of about $3.6 \%$ per annum. At that growth rate, by 2025 the population will almost be approximately to 63 million, close to that of Britain, which has a similar land mass where in 1950 UK had a population of approximately 50 million with an increment of 10 million in the year 2018 [1].

Population growth and migration has increased demand for agricultural land and firewood energy, and rural poverty restricts the ability to invest in sustainable land use practices. The population growth rate of $3.6 \%$ per anum leads to exerted

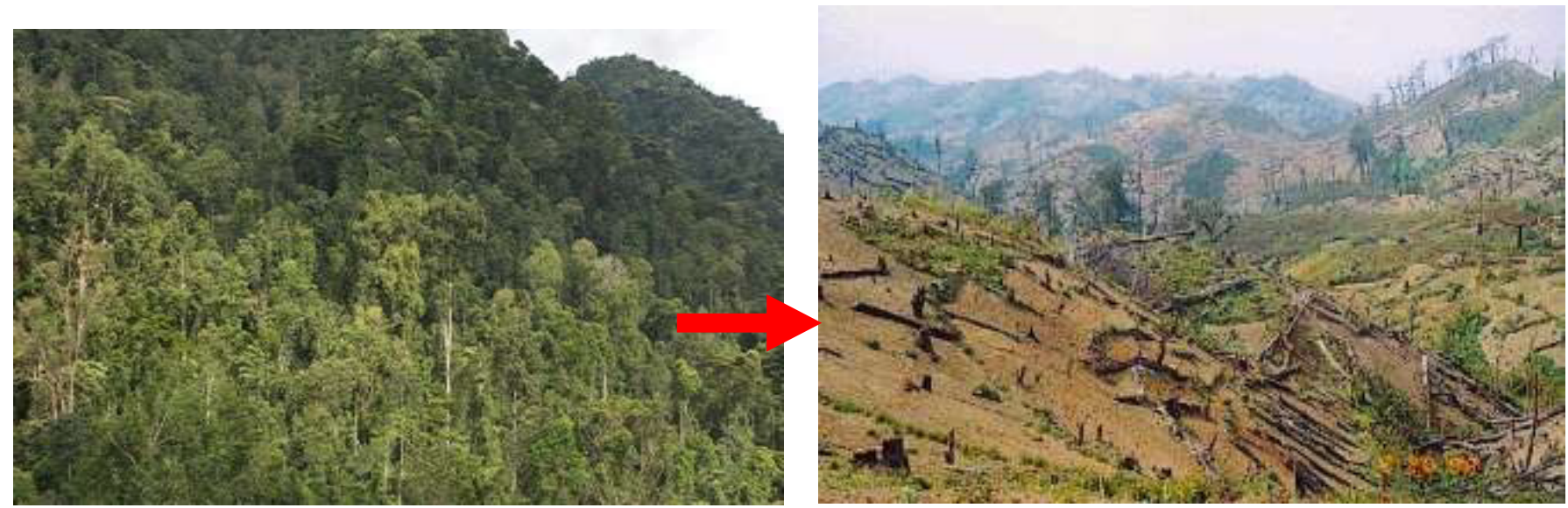

Figure 1. Deforestation in Uganda and Massive deforestation in Mpigi District. 
high pressure on the forest resources in order to derive people's livelihoods, higher population makes land for settlement and agriculture inadequate and consequently resort to the forest land (Table 1).

Therefore, deforestation is more in- tense in areas with high population densities. In districts such as Mukono, Mpigi and Luwero, major tracts of land have been cleared in the last decade. Much of this vegetation has secondary woody - Higher poverty levels over $46 \%$ of the people in Uganda live below the poverty line poor people are driven by the higher demand to sustain their livelihoods from the forest resources because they lack alternative sources of income as a consequence depletion of the forests become inevitable (Table 1) [2].

Following the trends, Uganda may not have any forests left in the next 83 years due to high population growth unless serious interventions are executed not only by Ugandan Government but also International Community (UNEP- United Nations Environment Program to assist Uganda in implementing environmentally sound policies and best practices, and other relevant Agencies).

Uganda is at risk of losing all its forests if deforestation in Uganda continues at its present rate there would be no forests left in 40 years.

Other reasons of deforestation include: poor rural electrification and costly electricity which makes $89 \%$ of Ugandans to use

Table 1. Showing population growth in Uganda.

\begin{tabular}{|c|c|}
\hline Year & Number of people \\
\hline 1911 & $2,500,000$ \\
\hline 1921 & $2,900,000$ \\
\hline 1931 & $3,500,000$ \\
\hline 1969 & $9,535,051$ \\
\hline 1980 & $12,636,179$ \\
\hline 1991 & $16,671,705$ \\
\hline 2002 & $24,227,297$ \\
\hline 2014 & $34,856,813$ \\
\hline 2100 & $\approx 43,746,516$ \\
\hline
\end{tabular}

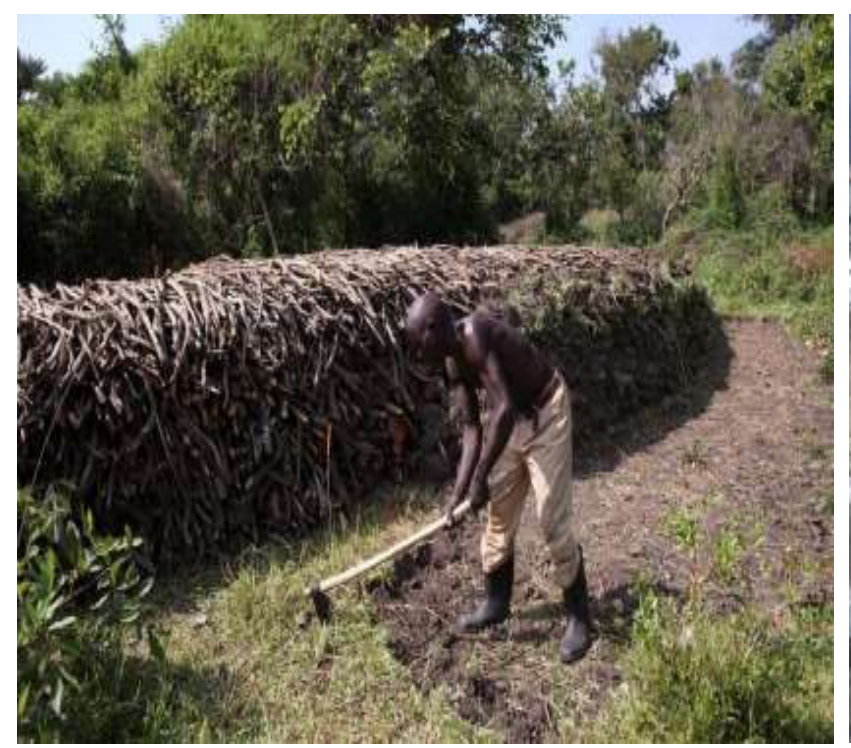

Figure 2(a). A man preparing for charcoal production (b) A poor woman selling charcoal as her source of income.

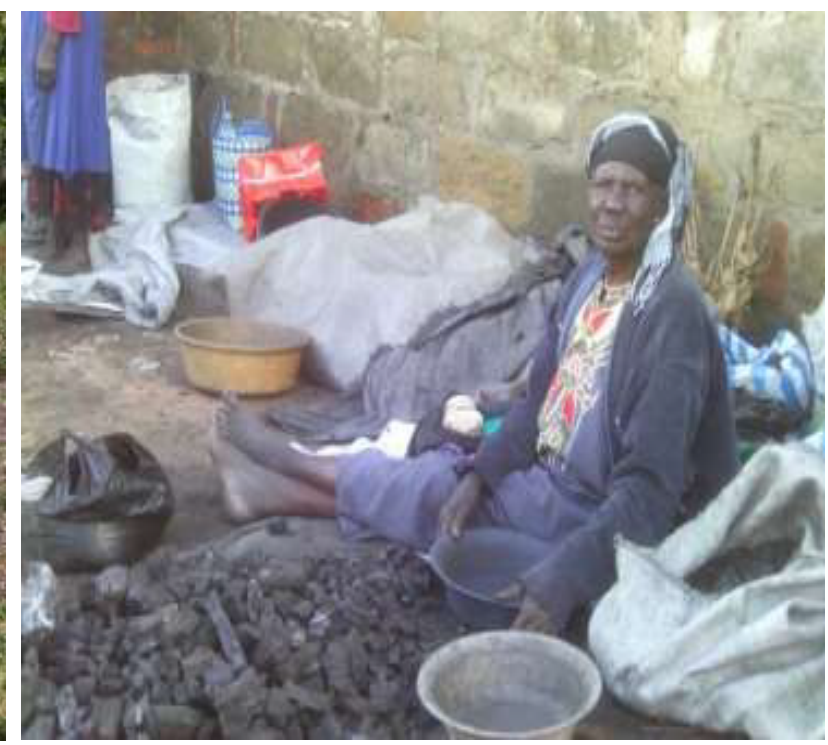

firewood and charcoal as the main sources of fuel to cook. Large amounts of forests are also spent as trees are cut for timber and wood because the construction industry still greatly use timber rather than steel and other substitutes (Figure $2 \mathrm{a}$ and $2 \mathrm{~b}$ ).

The people in the rural areas are among the first hit by the environmental negative effect of deforestation which include climate change, soil degradation reduced biodiversity and loss of recreation [3].

Degradation of water- shed areas is leading to deterioration of the quality of life and reduction of the options for development, Farmers are already struggling to adapt to the rapidly changing and increasingly erratic weather patterns since rain is not falling when it is supposed to and drought has left many farmers struggling to find enough food to feed their families.

In many districts of Uganda e.g. Tororo, Iganga, Nakasongola, Arua, Soroti, Kumi,Palisa, Rakai, Ajumani, the declining forest cover has resulted in a fuel wood deficit hence rising costs and increased burdens on women and children who collect firewood.

Therefore, if the situation is not reversed the knock on effect will be catastrophic and contributing to exacerbating soil degradation, decline food security, disease and conflict.

In the late $1980 \mathrm{~s}$, Approx. $75,000 \mathrm{~km}^{2}(31.7 \%)$ out of 236,040 $\mathrm{km}^{2}$ of total land in Uganda consisted of forest and woodland. Today, forests and woodlands cover is about $15.2 \%$ of Uganda's land surface meaning that Uganda has lost $16.5 \%$ of forests and woodland cover.

Over the last three decades, growth in human population and corresponding increase in demand for forest products for domestic and industrial use, expansion of agricultural land, illegal settlements and weak forest management capacity have adversely affected the status of natural forests in Uganda, particularly the biodiversity [4].

\section{Climate Change Impacts in Uganda}

There has been a 0.2 degree Celsius increase in temperatures every decade in Uganda since 1960 and may increase by up 
to 5.3 degree Celsius by 2080 . This means a lot because the increase in temperatures increases transpiration and water loss from soils, thereby destroying seedlings and crops. Rainfall projection will decrease by roughly $188 \mathrm{~mm}$ by 2080 and also a shift of seasons.

Climate change has altered the competitive position of Uganda with respect, for example, to exports of agricultural products. This may result from yields increasing as a result of altered climate in one area, whilst being reduced in another. In Bushenyi district Banana harvest has shown consistent increase trend while Masaka district, harvest has drastically decreased.

The altered competitive position may affect not only exports, but also regional and farm-level income, rural employment, and the type of crops grown in a region. While most studies are unlikely to include an analysis of competitiveness itself, it is possible to evaluate the relative position of a country by studying the few analyses of climate change effects on global food trade [5].

The country is highly vulnerable to climate change and variability thus, its economy and the wellbeing of its people are tightly bound to climate. Human induced climate change today has the potential to halt or reverse the country's development trajectory. It is the poor and vulnerable people in remote and hard to reach areas who feel these impacts the hardest, though climate change has a serious implications for the nation's economy previously, with for example, a shift in the viability of coffee growing areas potentially wiping out US \$265.8 million or $40 \%$ of export revenue in the year 2016 (Figure 3).

The Uganda is highly vulnerable to climate change and variability thus, its economy and the wellbeing of its people are tightly bound to climate. Human induced climate change today has the potential to halt as well as reverse the region's development trajectory.

Given that Uganda is a landlocked country that depends on agricultural, agro-pastoral, and pastoral livelihoods, the population expansion has placed increasing stress on limited natural resources i.e. forests and woodland have been destroyed.

Cropping regions in most parts of Uganda appear most affected by the observed changes in climate. Rainfall has declined in the West and North East threatening Uganda's future food production prospects [5].

The general level of food insecurity in Uganda has started rising at the beginning of the year 2017, 40 people died because of famine as a result of prolonged drought and over 1,000,000 people were surviving on 59,000 tons of Rice donated by the Government of China as part for good working relationship between Beijing and Kampala.

Pastoralists in the northeast, especially in Karamoja are facing chronic food insecurity. More frequent droughts decrease their resilience, as well as the resilience of pastoralists and agropastoralists in areas of Kasese (Kyinyamaseke, Katunguru, Hamukungu, Bugoye, Rugendabala), Isngiro among others. It is clear that climate change is a serious issue that requires research for solutions and effective policies to allow the general population meet needs while protecting the environment (Figure 4).

\section{Recommendations}

Despite the existence of forestry related policies such the Uganda forestry policy and the National Environment Management Policy which were designed to protect and preserve forest ecosystems, there still exists rampant deforestation in Uganda today and the policies that currently exist are part of the problem. These need to be reformed as listed above and the reform should involve all stakeholders so that implementation is simplified. However institution irregularities such as corruption need to be given adequate attention for any success of reviewed policies to be achieved.

1. Promoting activities that reduce the pressure off the forest like sericulture, butterfly farming, improved bee-

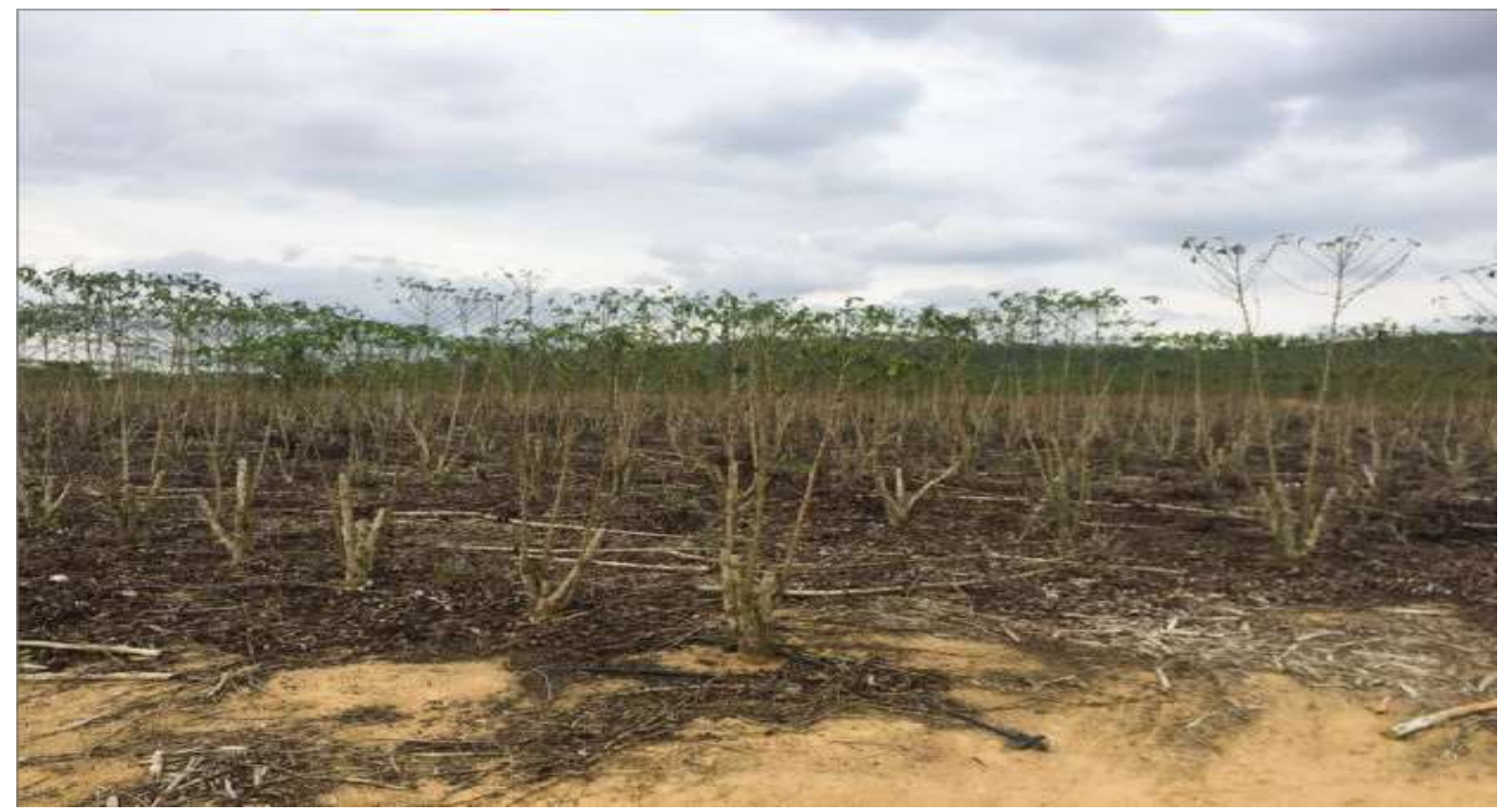

Figure 3. Coffee Plantation affected by Drought in Western Uganda. 

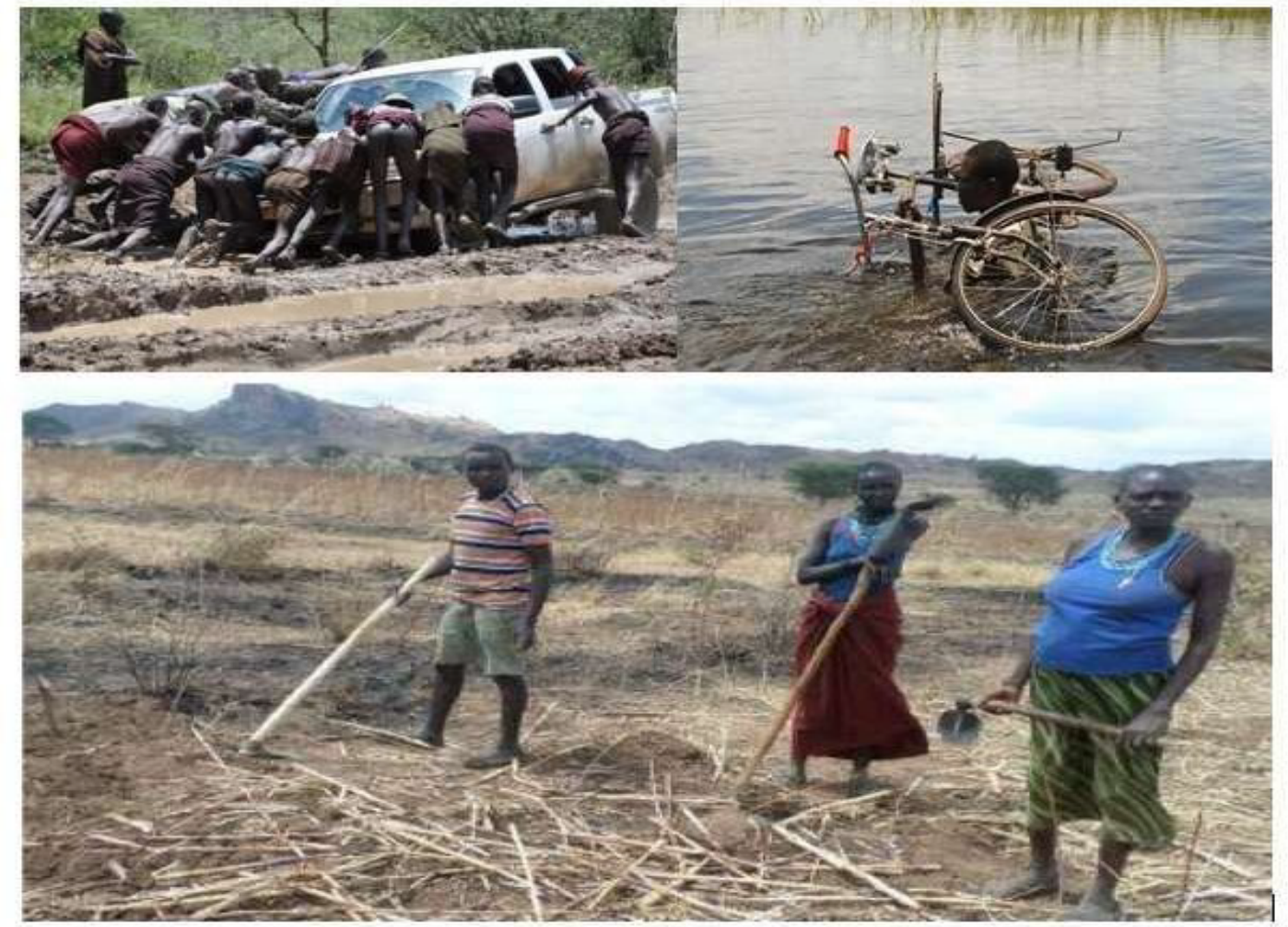

Figure 4. The adverse impacts of climate change have not spared Uganda particularly in last decade as evidenced by numerous episodes of erratic rainfall patterns, prolonged droughts, flooding, recurrence of mudslides, thunderstorms, increased incidence of pests and diseases, famine and declining agriculture productivity.

keeping, development of fodder banks, bio-intensive agriculture and farm forestry. And should be extremely active and vigorous around the forests resources Increase per capita income and check on the population growth.

2. Increasing income and improved literacy levels because with improved standards of living, over dependence on forest products for example as a source of energy is checked and land use change due to literacy.

3. Private land owners with natural forest cover on their land should be given direct monetary or other incentives to encourage them to limit deforestation. Forest product and service valuation: monetary digits are more easily understood by the public. Forest goods and services should be explored and a value attached to them so that a lay-man can understand.

4. Investment in research, education and extension services: Educating stakeholders helps them understand how to prevent and reduce adverse environmental effects associated with deforestation. Extension services are also crucial because certain class of people have the information, however passing it on to the stakeholders is another challenge that can be addressed through extension.

5. The government in addition is required to put in place a regulatory framework, which will create a positive investment climate to encourage private sector investment in commercial forest plantations. The government is required, amongst other tasks, to set out priority areas for the development of carbon storage plantations in different areas of Uganda.

\section{Conclusion}

Over $80 \%$ of Uganda's population is rural and depends on rain-fed agriculture, which is vulnerable to impacts of adverse effects of climate change. While Uganda's climate offers a great potential for food production, the prolonged and frequent droughts in many parts of the country, particularly the northeast, have led to almost perpetual dependency on food aid. A typical example is in the arid areas of Karamoja where the World Food Programme supplies virtually all the food due to hunger following the prolonged dry spells that rendered a food accessibility a nasty challenge.

The dry spells also hit hard in neighbouring districts of Katakwi, Amuria, Soroti, Kumi and Serere in Teso Sub region. The severe lack of food and drinking water for both humans and animals has compounded the already dreadful situation forcing multitude to flee to areas with food.

\section{References}

1. http://www.envalert.org

2. Ministry of Water and Environment. State of Uganda's Forestry Report. 2016.

3. National Environment Management Authority. National State of Environment Report for Uganda, NEMA House, Kampala. 2016.

4. National Forestry Authority. Uganda's Forests, functions and classification. NFA, Kampala, Uganda. 2005. 
5. Sustainable Development Centre. Value Chain Analysis of the Charcoal Enterprise in Uganda. 2010.

\section{*Correspondence to:}

Josephat M

Retired Heat Transfer Expert

Petroleum Production and Geoscience- Makerere

University

Dept. Wildlife and Natural Resources- Uganda

Wildlife Research \& Training Institute

Africa natural Resources Institute

Kampala

Uganda

East Africa

Tel: +256771266880

E-mail:.jmusa@afnri.com 